\title{
Valores de referência de parâmetros bioquímicos no sangue de duas linhagens de camundongos
}

\author{
Reference values for blood-based biochemical parameters in $B A L B / C$ and $C 57 B L / 6$ wild-type mice
}

Aline Silva Almeida'; Ana Carolina Guimarães Faleiros ${ }^{2}$; David Nascimento Silva Teixeira; Ulisses Antônio Cota ${ }^{4}$; Javier Emilio Lazo Chica ${ }^{5}$

unitermos
Análises laboratoriais
Dosagens bioquímicas
Camundongos BALB/C
Camundongos C57BL/6
selvagens
Valores de referência

\section{resumo}

Introdução: Conhecer os parâmetros bioquímicos individuais de animais de laboratório utilizados na experimentação é importante, pois eles servirão como parâmetros para avaliar alterações funcionais em órgãos e como base para estabelecer valores de referência. Objetivo: Estabelecer valores de referência bioquímicos do sangue em camundongos das linhagens $\mathrm{BALB} / \mathrm{C}$ e C57BL/6 selvagens do Biotério da Disciplina de Biologia Celular da Universidade Federal do Triângulo Mineiro (UFTM). Materiais e métodos: Foram utilizados 30 camundongos (BALB/C e C57BL/6 selvagem). Os exames realizados foram glicose, triglicérides, colesterol, proteínas totais, albumina, amilase, ácido úrico, uréia, fosfatase alcalina (kits Wiener), e as determinações foram realizadas no equipamento BIOPLUS-2000. Resultados: Entre os nove analitos observou-se que quatro (albumina, glicose, proteínas totais e colesterol) apresentaram diferenças estatisticamente significativas entre as linhagens. Padronizamos como valores de referência para os camundongos os valores do intervalo de confiança (IC). Nos analitos em que houve diferença significativa entre as linhagens $(p<0,05)$ adotamos os valores do IC de cada linhagem; para os que não apresentaram diferenças foram utilizados os valores mínimos e máximos do IC entre as duas linhagens. Conclusão: Ao final da análise, acreditamos que os resultados obtidos sugerem a padronização de intervalos de referência próprios de cada biotério, pois refletem a condição da população para os quais os testes serão aplicados no dia-a-dia.

\section{abstract}

Introduction: Identifying individual biochemical parameters of laboratory animal species is important inasmuch as they may be used in the evaluation of functional changes in organs and in the establishment of reference values. Objective: To establish biochemical reference values for blood tests in BALB/C and C57BL/6 wild-type mice from the Vivarium of the Department of Cellular Biology at the Federal University of "Triângulo Mineiro". Materials and methods: Thirty wild-type mice of the lineages $B A L B / C$ and $C 57 B L / 6$ were used to evaluate the serum levels of glucose, triglycerides, cholesterol, total protein, albumin, amylase, uric acid, urea and alkaline phosphatase. The determinations were performed in a BIOPLUS-2000 analyzer. Results: Four out of the nine analytes (albumin, glucose, total proteins and cholesterol) showed significant statistical differences between the strains. Confidence interval $(\mathrm{Cl})$ values were standardized as reference values. In those analytes in which there was significant difference between strains $(\mathrm{p}<0.05)$, confidence interval values of each lineage were adopted, whereas in those ones in which there were no differences, the minimum and maximum values of confidence interval from both lineages were applied. Conclusion: The results show the need for reference interval standardization of each Vivarium inasmuch as it reflects the conditions of the population in which the tests will be routinely performed. key words

Laboratorial Analysis:

Biochemical analysis

$B A L B / C$

Wild-type C57BL/6

Reference values

\footnotetext{
1. Biomédica; mestre em Patologia pela Universidade Federal do Triângulo Mineiro (UFTM); disciplina de Biologia Celular da UFTM.

2. Biomédica; mestre em Patologia pela UFTM; professora assistente da Disciplina de Biologia Celular da UFTM.

3. Biólogo; pós-doutorado pela UFTM; professor adjunto da disciplina de Laboratório Clínico da UFTM.

4. Médico; especialista em Patologia Clínica pela UFTM.

5. Médico; doutor em Patologia pela UFTM; professor adjunto da disciplina de Biologia Celular da UFTM.

Trabalho realizado no Departamento de Ciências Biológicas da UFTM.

Apoio financeiro: Fundação de Amparo à Pesquisa do Estado de Minas Gerais (FAPEMIC).
} 


\section{Introdução}

A utilização de animais de laboratório em pesquisa científica tem sido de fundamental importância, não só pelos avanços que permite ao conhecimento dos mecanismos dos processos vitais, mas também ao aperfeiçoamento dos métodos de prevenção, diagnóstico e tratamento de doenças tanto na medicina humana como na própria medicina veterinária ${ }^{(4,7,9)}$.

Ao estabelecer intervalos de referência para qualquer parâmetro, algumas características devem ser consideradas: idade, sexo, raça, fatores ambientais, estado nutricional, grau de atividade física, período de ciclo menstrual, uso de medicamentos, existência de doença crônica etc. ${ }^{(1,11)}$. É conhecido que ratos e camundongos podem exibir variações dos parâmetros bioquímicos relacionadas com sexo, linhagem e genótipo, podendo ser influenciados pela idade, pela dieta, pelo manuseio, pelo meio ambiente, entre outros fatores ${ }^{(8)}$. Por essa razão, o conhecimento dos valores dos diferentes parâmetros fisiológicos é critério importante para a avaliação da homeostase, das modificações induzidas por processos patológicos e dos resultados obtidos nos procedimentos experimentais ${ }^{(9)}$.

Até o momento, as listas de referência de valores bioquímicos do sangue são gerais, não especificam linhagem de camundongos ${ }^{(6,10,12)}$ ou fazem pool, mistura de soro( ${ }^{(2)}$. A utilização de pool ocorre, provavelmente, devido ao fato de que se obtém volume muito pequeno de soro de cada animal. O objetivo deste estudo é estabelecer uma lista de referências de valores bioquímicos do sangue em camundongos das linhagens BALB/C e C57BL/6 selvagem do Biotério da Disciplina de Biologia Celular da Universidade Federal do Triângulo Mineiro (UFTM).

\section{Materiais e métodos}

Amostras biológicas foram retiradas de 30 camundongos, 15 da linhagem C57BL/6 selvagem e $15 \mathrm{BALB} / \mathrm{C}$, machos, jovens, divididos em grupos de cinco animais, em gaiolas plásticas de $414 \mathrm{~mm} \times 344 \mathrm{~mm} \times 168 \mathrm{~mm}$. Os animais foram mantidos em sala especial, com renovação constante de ar, à temperatura de $20^{\circ} \mathrm{C}$ a $26^{\circ} \mathrm{C}$ e umidade entre $45 \%$ e $55 \%$. A alimentação foi feita com ração comercial de composição conhecida e água oferecida ad libitum.
As amostras de sangue foram colhidas dos camundongos pelo plexo retro-orbital com o auxílio da pipeta Pasteur contendo heparina. O sangue total foi centrifugado a $1.831 \mathrm{~g}$ por três minutos para separação do plasma. Os exames laboratoriais foram feitos no aparelho BIOPLUS-2000, utilizando kit da marca Wiener. Através da metodologia colorimétrica de ponto final, foram determinados os seguintes parâmetros bioquímicos: albumina (verde de bromocresol), glicose (glicose oxidase [GOD]), proteínas totais (biureto), colesterol total (colesterol oxidase), triglicérides (glicerol fosfato oxidase [GPO]), uréia (urease $[G L D H]$ ), ácido úrico (uricase). O método cinético enzimático foi o escolhido para determinações da amilase (método de Caraway modificado) e da fosfatase alcalina (método de Roy modificado). Todos os ensaios tiveram acompanhamento dos controles de qualidade.

A normalidade e a homogeneidade foram verificadas pelo método de Kolmogorov e Smirnov e pelo teste de Bartlett, respectivamente. Para comparar os grupos foi utilizado o teste $t$ com correção de Welch. Os resultados foram expressos em média \pm desvio padrão (DP). Os valores discrepantes (outliers) foram verificados através do teste de Grubbs. As diferenças foram consideradas significativas quando $p$ foi menor que 0,05 .

Este trabalho segue os princípios éticos de experimentação animal do Colégio Brasileiro de Experimentação Animal (COBEA) e as normas estabelecidas no Guide for Care and Use of Laboratory Animals (Institute of Laboratory Animal Resources, Commission on Life Science, National Research Council, Washington, DC, 1996).

\section{Resultados}

Na Tabela 1 estão descritos a média, o DP e os intervalos de confiança (IC) dos analitos realizados entre as linhagens dos camundongos. Entre os nove analitos descritos na Tabela 1 observa-se que quatro $(44,4 \%)$ apresentaram diferenças estatisticamente significativas entre as linhagens.

De acordo com os valores apresentados na Tabela 1, podemos padronizar como valores de referência para os camundongos das linhagens BALB/C e C57BL6 os valores do IC. Nos analitos onde houve diferença significativa entre as linhagens $(p<0,05)$, adotamos os valores do IC de cada linhagem; para os que não apresentaram diferenças foram utilizados os valores mínimos e máximos do IC entre as duas linhagens (Tabela 2). 
Tabela 1

Analito

Albumina (g/dl)

Glicose (mg/d)

P. totais (g/dl)

Colesterol (mg/dl)

Triglicérides ( $\mathrm{mg} / \mathrm{dl})$

Uréia $(\mathrm{mg} / \mathrm{dl})$

Ácido úrico (mg/dl)

Amilase (U/I)

F. alcalina (U/l)

Valores da média, DP e IC dos analitos analisados no plasma de camundongos

DP: desvio padrão; IC: intervalo de confiança; *teste $t$ com correção de Welch.

\section{$\operatorname{BALB/C}(n=15)$}

Média \pm DP (IC)

C57BL6 $(n=15)$

Média \pm DP (IC)

$p^{*}$

$$
\begin{array}{ccc}
1,23 \pm 0,15(1,14-1,31) & 1,74 \pm 0,49(1,46-2,02) & p>0,05 \\
80,75 \pm 20,25(69,53-91,96) & 115,37 \pm 35,52(95,69-135,05) & p>0,05 \\
5,14 \pm 0,53(4,85-5,44) & 6,49 \pm 0,73(6,08-6,9) & p>0,05 \\
71,78 \pm 13,85(64,11-79,45) & 60,22 \pm 16,73(50,95-69,49) & p>0,05 \\
26,93 \pm 4,76(24,18-29,68) & 25,22 \pm 7,42(21,11-29,33) & p>0,05 \\
51,2 \pm 15,92(42,37-60,02) & 47,53 \pm 10,03(41,97-53,09) & p>0,05 \\
1,25 \pm 0,59(0,91-1,58) & 1,54 \pm 0,68(1,16-1,92) & p>0,05 \\
765,07 \pm 132,27(688,71-841,43) & 723,29 \pm 154,6(634,04-812,53) & p>0,05 \\
267 \pm 84,21(210,43-323,57) & 243,08 \pm 51,13(212,18-273,98) & p>0,05
\end{array}
$$

Valores de referência de parâmetros bioquímicos independentes da

\section{Tabela 2}

Analito linhagem (BALB/c e C57BL6)

$\begin{array}{lc}\begin{array}{l}\text { Triglicérides } \\ \text { (mg/dl) }\end{array} & 21,11-29,68 \\ \text { Uréia (mg/dl) } & 41,97-60,02 \\ \begin{array}{l}\text { Ácido úrico } \\ \text { (mg/dl) }\end{array} & 0,91-1,92 \\ \text { Amilase (U/l) } & 634,04-841,43 \\ \begin{array}{l}\text { F. alcalina } \\ \text { (U/l) }\end{array} & 210,43-323,57\end{array}$

\section{Discussão}

Os intervalos de referências de valores laboratoriais se tornam um desafio nos animais de laboratório já que as bulas dos reagentes estão padronizadas para humanos. Para determinar um intervalo de referência devem ser avaliadas as variáveis biológicas, como ritmos biológicos, gênero, idade e variedade genética ${ }^{(8)}$. De acordo com a Organização Mundial de Saúde (OMS), a Federação Internacional de Química Clínica (IFCC) e o Instituto de Padronização Clínica e Laboratorial (CLSI), em humanos o valor de referência é definido como um resultado obtido pela mensuração quantitativa dos analitos com base nos critérios definidos ${ }^{(3)}$.

O diagnóstico laboratorial de doenças que acometem camundongos é prejudicado pela dificuldade de coleta das amostras, pela técnica laboratorial para pequenos volumes e pela falta de valores de referência para comparação. Os dados da literatura referentes aos camundongos, não especificam linhagem ${ }^{(6,10,12)}$ ou fazem pool (mistura de soro e/ou plasma) ${ }^{(2)}$.

$\mathrm{Na}$ literatura, as informações que dizem respeito à mensuração de parâmetros bioquímicos em camundongos BALB/C e C57BL6 são escassas e, por isso, encontramos dificuldades na comparação dos resultados obtidos. Na análise dos níveis séricos, encontramos que a maioria dos analitos está de acordo com a literatura consultada ${ }^{(10,12)}$, porém esses autores não mencionam quais as linhagens utilizadas para elaborar os valores de referência. Em relação às dosagens dos níveis séricos de amilase não podemos fazer comparação com outros dados da literatura, pois não há relatos que sejam do nosso conhecimento.

A diferença encontrada no nosso trabalho em comparação a outros autores( ${ }^{(2)}$ provavelmente ocorreu devido às diferenças entre as linhagens, pelas condições físicas e climáticas e metodologia utilizada. Dessa forma, através da obtenção dos valores de referência para os camundongos machos das linhagens BALB/ c e C57BL6, recomendamos que as análises sejam feitas individualmente e por linhagem de camundongo para os analitos albumina, glicose, proteínas totais e colesterol. Já para os analitos triglicérides, uréia, ácido úrico, fosfatase alcalina e amilase, não encontramos diferença significativa entre as linhagens de camundongos, e apesar de o valor de referência ser o mesmo, recomendamos que as dosagens sejam feitas separadamente e não em pool, visto que cada linhagem apresenta características próprias. 


\section{Conclusão}

Ao final da análise, acreditamos que os resultados obtidos sugerem a padronização de intervalos de referência próprios de cada biotério, pois refletem a condição da população para a qual os testes serão aplicados no dia-a-dia.

\section{Agradecimentos}

Aos funcionários da Disciplina de Biologia Celular; à UFTM; aos órgãos de fomento Fundação de Ensino e Pesquisa de Uberaba (FUNEPU), FAPEMIG, Conselho Nacional de Desenvolvimento Científico e Tecnológico (CNPq) e Coordenação de Aperfeiçoamento de Pessoal de Nível Superior (CAPES) e ao Laboratório LAMEL, pelas suas contribuições na realização deste trabalho.

\section{Referências}

1. ANDRIOLO, A. Medicina laboratorial. 1. ed. São Paulo, SP: Ed. Manole, 2005.

2. CENTRO DE BIOTERISMO DA FACULDADE DE MEDICINA DA UNIVERSIDADE DE SÃO PAULO (USP). Parâmetros dos principais animais de experimentação. 2000. Disponível em: http://www.biot.fm.usp.br/site1/index2.html. Acesso em: 29 de abril de 2005.

3. CLINICAL AND LABORATORY STANDARDS INSTITUTE. How to define and determine reference intervals in the clinical laboratory. Document C 28-A2, 2000.

4. COOK, M. The anatomy of the laboratory mouse. New York, NY: Academic Press, 1986.

5. FERREIRA, C. E. S.; ANDRIOLO, A. Intervalos de referência no laboratório clínico. J Brás Patol Med Lab, v. 44, n. 1, p. 11-16, 2008.

6. FOSTER, H. L.; SMALL, J. D.; FOX, J. G. The mouse in biomedical research. New York, NY: Academic Press, 1982.
7. FRANCO, M. Centro de desenvolvimento de modelos experimentais: CEDEME/COBEA da Universidade de São Paulo. Disponível em: http://www.cobea.org.br/ animais.html. Acesso em: 15 de junho de 2005.

8. GOWEN, J. W.; CALHOUN, M. L. Factors affecting genetic resistance of mice to typhoid. J Infect Dis, v. 72, p. 40-56, 1983.

9. GREEN, E. Biology of the laboratory mouse. New York, NY: McGraw-Hill Book Co., 1986.

10. HARKNESS, J. E.; WAGNER J. Biologia e clínica de roedores. São Paulo, SP: Livraria Roca Ltda., 1993.

11. McCLATCHEY, K. D. Clinical laboratory medicine. In: HOLMES, A. C. The interpretation of laboratory tests. $2^{\text {nd }}$ ed. Philadelphia: Lippincott Williams \& Wilkins, 2002. Sec. 4; p. 97-122.

12. MITRUKA, B. M.; RAWNSLEY, H. M. Clinical biochemical and hematological reference values in normal experimental animals. New York, N.Y.: Masson Publishing, 1977. 